\title{
The role of industrial energy storage solutions in a distributed energy system: empirical findings and implications on cooperative ties
}

\author{
Dominik Halstrup $^{\mathrm{a}}$, Marlene Schriever ${ }^{\mathrm{b} *}$ \\ ${ }^{a}$ University of Applied Sciences Osnabrueck, Caprivistrasse 30A, 49076 Osnabrueck, Germany \\ ${ }^{b}$ University of Applied Sciences Osnabrueck, Caprivistrasse 30A, 49076 Osnabrueck, Germany
}

\begin{abstract}
Current Renewable Energy sources are mainly fluctuating by nature, which is why one of the main interests in an energy system with high Renewable Energy contribution is the flexibilization of supply and demand. One measure of flexibilization can be Energy Storage Solutions. Whereas the residential use of Energy Storage Solutions has been a subject of interest to researchers, the organizational perspective has been neglected in certain areas. Even though, especially the industry, as one of the main energy consumer, is of critical importance along the way of transforming the energy system to Renewable Energies. Especially the distributed character of the Energy Transition in Germany demands for further flexibility being introduced to the grid. This study therefore examines the acceptance of electric Energy Storage Solutions among the German manufacturing industry. Based on quantitative data from a sample of 101 German manufacturing companies, the article analyzes the general awareness about Energy Storage Solutions, possible acceptance factors and perspectives on new possible areas of cooperation. The results show that organizations in the sample display general knowledge about Energy Storage solutions but do not have in-depth knowledge about modes of deployment. The organizations in question agree on the fact that future cooperation is necessary in order to guarantee supply security and quality of electric energy.
\end{abstract}

Keywords: Distributed energy system; Energy Storage Solutions; Manufacturing industry; German Energy Transition; Adoption, Diffusion

\section{Introduction}

The increasing penetration of distributed generated energy, often highly fluctuating, can have a negative impact on energy systems; in particular the distribution grid is facing difficulties in the mentioned scenario [1]. Energy Storage Solutions (ESS) are discussed as a possibility to provide local energy balancing and ancillary services. Predictions of the actual storage capacity needed in Germany are widely investigated in different studies and differ from 0 to $32 \mathrm{GW}$ at a Renewable Energy contribution over $80 \%$ due to different scenarios and variables [2].

While looking at possible business models to support the adoption and diffusion of ESS, especially cooperative business models for ESS are of interest because they offer the possibility to combine a variety of usages/services and simultaneously mitigate Renewable Energy between supply and demand. Following a recognizable trend in the storage industry this paper focuses on electrochemical battery storage only as it offers the possibility of short time load deferral and is anticipated to decrease in costs [3]. When pursuing distributed energy production, the question arises how the integration of ESS in the

\footnotetext{
* Manuscript received November 12, 2017; revised January 5, 2018.

Corresponding author. Tel.: +4917662405204; E-mail address: m.schriever@hs-osnabrueck.de.

doi: $10.12720 /$ sgce.7.1.53-63
} 
grid can be achieved and by whom. Up until now, research on the adoption and acceptance of Renewable Energy Technologies (RET) in Germany has mainly focused on the household perception of the adoption process, even though in 2014 the industry can be held responsible for over $45 \%$ of the total electric energy consumption [4].

Shedding further light on the target group of industrial consumers, such as manufacturing companies can lead to a better understanding of the acceptance and diffusion of ESS in a distributed energy system. Most RET are, like ESS, capital intensive technologies and require high up-front investments [5]. This leads to relatively long payback periods, which currently do not seem acceptable for organizations in a fast changing environment in transition, such as the German Energy Transition. In order to understand the adoption process of capital-intensive RET such as ESS in companies, it is required to gain a better understanding of factors influencing the decision and the current level of awareness amongst the target group of the manufacturing industry.

The presented research therefore addresses the following questions: (1) What is the general awareness amongst companies in the project region regarding ESS and their uses in an industrial setting, (2) which factors influence the acceptance of ESS in an industrial setting and (3) what could be the future role of cooperative ESS business models in a distributed energy system. Results are drawn from a quantitative study conducted in late 2016 in which 101 manufacturing companies participated.

The paper first discusses the role of ESS in an energy system dominated by distributed energy generation as well as possible modes of deployment of ESS in an industrial setting. Section 3 focuses on the methodology of the study and the underlying concept of acceptance of the research presented, whereas Section 4 presents the obtained results from the data set following the acceptance model developed earlier. The paper closes with a conclusion of findings on the role of ESS in a distributed energy system as well as cooperative ESS business models to enhance the diffusion of ESS.

\section{Background and Theoretical Framework}

\subsection{The role of ESS in a distributed energy system}

The exploitation and implementation of RET can be problematic due to its fluctuating and intermittent nature [6]. With almost $70 \%$ of the generated electricity being generated by fossil fuels, fossil fuel plants are currently mainly responsible for the power network stability and load management [7]. Amongst many approaches to realize network stability and reliability without having to use fossil fuels, such as demand side management or interconnection of different grids, ESS are seen as a promising technology [7]. As explained by Lund et al. ESS can benefit the grid in general and the integration of Renewable Energy in particular in different forms: (1) helping in meeting peak electrical load demands, (2) providing time varying energy management, (3) alleviating the intermittence of renewable source power generation (4), reassuring power quality/reliability by maintaining voltage levels, (5) meeting remote and vehicle load needs, (6) supporting the realization of smart grids, (7) helping with the management of distributed/standby power generation and (8) reducing electrical energy import during peak demand periods [8]. Whereas Pumped Hydroelectric Storage has almost been used to its capacity in Germany and many other countries like the UK [7], electrochemical ESS, such as lithium-ion batteries are scalable and do not require special landscape architecture.

In a distributed and decentralized energy system ESS can back-up, stabilize or smoothen the fluctuating Renewable Energies as well as ramping and load following activities. Additionally ESS can be used for time shifting and peak shaving activities in order to generate additional financial returns as shown in section 2.3. Most importantly, however, ESS are able to stabilize the transmission and distribution grid by addressing short-term imbalances in the power supply/demand, a task traditionally managed by operating reserves or other ancillary services [9]. The operative integration of ESS in the energy system is both a technical and a socio-economic question since the technical capabilities of ESS need to meet the requirements and the market design determines the rate of diffusion of ESS [9]. The compensation of certain services, such as generating capacity, or provision of ancillary services, that ESS 
can offer seems to be key for the market integration and is currently only with limitations part of the German market design. The variety of possible combinations and different services that are possible for ESS, make the case of a single device (ESS) providing multiple services a difficult business case to assess. In the field of industrial users, large-scale ESS as it would be the case for the facilities providing grid services come into play when addressing shared ESS like explained by Rahbar et al. [10]. Simultaneously, small-scale ESS in a distributed energy system can be grouped and provide afore mentioned services. Beside the technical and economic feasibility, the social component namely the acceptance of such storage solutions and related business models as researched in this paper is of importance.

\subsection{Energy storage solutions in an industrial setting}

Possible areas for EES implementation in an industrial setting can be described from two different angles. They can either be implemented on the system side or the customer side [3]. Beneficial from a system point of view is the implementation to supply Control Energy when needed in order to balance the voltage. In an industrial setting electric ESS are especially of interest to implement load management, meaning a temporal deferral of load capacity, for peak-shaving activities and the possibility to achieve higher consumption rates of self-generated electricity [11].

Depending on the given load profile of the organization, peak-shaving can be used to lower the annual peak load and by that the capacity charge [12]. Due to the need to especially smoothen short-term fluctuations and defer loads in a small time span, electrochemical ESS are because of their technical suitability of special interest [3]. If the production process of the organization in question is prone to short-term power cuts as it is especially the case in chemical industries, EES can be implemented to bypass planned or unplanned power cuts that would otherwise mean financial loss [3].

When combined with self-owned power generation facilities such as PV, ESS in organizations are useful to increase the amount of self-consumed energy of the energy produced [13]. Instead of feeding the generated electricity into the grid, the generated power is stored in ESS and will be used up later. If variable feed-in tariffs are installed, recharge and discharge at a certain point of time can become financially more attractive [14]. In order to assess the timing smart technologies can support the process and increase flexibility in times when the electricity market offers the highest yields [15]. If an industrial consumer achieves a relatively high level of flexibility already as of today the control energy market in Germany offers potential to generate returns. Of special interest for customers in the German electricity market is the so called minutes reserve as it needs to be made accessible within 15 minutes in the course of a scheduled supply [15].

With regard to the relatively high upfront investment required to install ESS and the aforementioned relatively long payback period, the presented application fields are only feasible under certain circumstances and require special attention in the organizations capital budgeting [16]. In order to fully and thoroughly assess whether or not the installation of ESS is feasible and profitable, organizations need to undergo a single case-related analysis of load profiles. Due to different characteristics in load profile and electricity demand possible areas of application cannot be generalized and looking at it from a business point of view the installation of ESS is only profitable for a subset of the organizations in Germany [17].

The installation of ESS is therefore presumably especially in manufacturing companies beneficial as to the fact that they -due to production and processing- have a load profile characterized by peaks and a relatively high demand of energy [18]. Organizations that can plan their demand of electricity relatively flexible or where production processes might be altered accordingly at relatively low cost are seemingly a good option to install ESS [15].

A combination of all or some of the presented possible applications of ESS seems more promising as it offers higher potential to generate returns. Vogt et al. show based on an example of a pilot project the combination of increased self-consumption rate of electricity and peak-shaving in an industrial MicroGrid [19]. In the course of a simplified investment calculation they draw the conclusion that the installation of ESS can be profitable with a payback period of 10 years. 


\section{Theory/Methodology}

\subsection{Model of acceptance}

Questions regarding the acceptance of innovative energy technologies have been of special interest over the last years and researchers as well as practitioners have contributed to a wide array of viewpoints [20-25]. Whereas the literature on infrastructural energy technologies, such as transmission lines and wind parks in Germany is relatively rich; research on other technologies such as ESS is still lacking [25]. Nevertheless, first approaches are taken in the field of acceptance of ESS in particular, such as the acceptance of large ESS-Parks [26] as well as different business models for the deployment of ESS on the household level [27]. Far fewer articles and research papers address the organizational perspective on ESS [12]. Therefore, it can be stated that the scientific discussion regarding ESS in an industrial setting especially lacks research findings that are based on empirical data.

Acceptance has been measured in a number of different areas and therefore found its way into various different definitions. Acceptance is by far not a uniformed term. In this particular research, the acceptance definition derives from Mueller-Boeling and Mueller and can be understood as the positively connoted decision of an individual/organization towards future usage [28]. Unlike other definitions, the mere lack of resistance is not considered to be part of acceptance; it has therefore a strong active component [29].

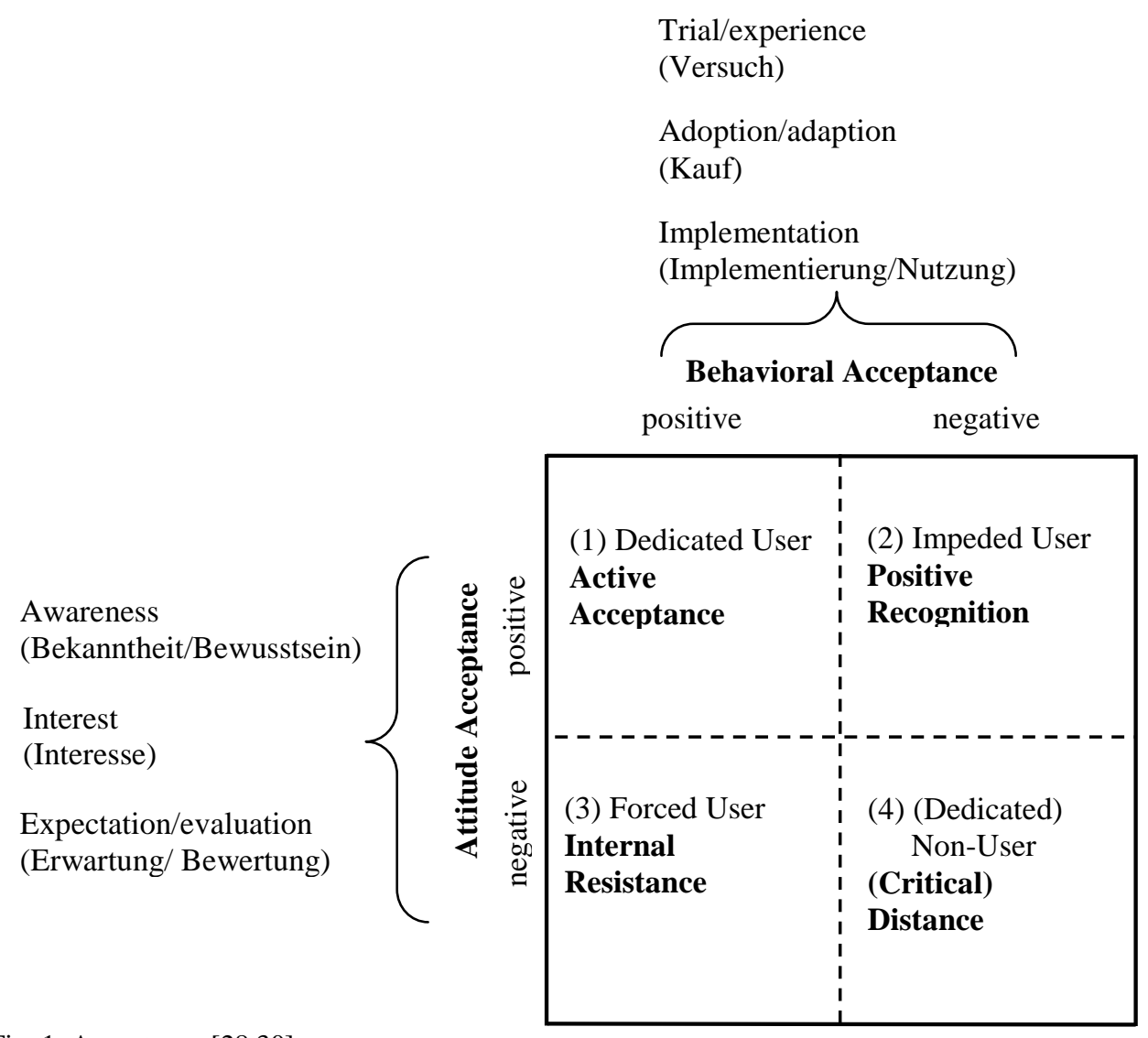

Fig. 1. Acceptance $[28,30]$

Following Mueller-Boeling and Mueller Acceptance is understood as a phenomenon divided into two dimensions: attitude and behavior [28]. In the research presented, the classical definition of Acceptance was extended by the sub dimensions of Awareness, Interest and Expectation/Evaluation as well as 
Trial/experience, Adoption/Adaption and Implementation originating from the dynamic acceptance approach of Kollmann [30]. The latter dimensions were added as to refer to the level of knowledge regarding ESS of the organizations in more detail and to differentiate the dichotomous view of MüllerBöling and Müller with regard to the level of knowledge [28,31].

Attitude acceptance is a cognitive and affective orientation of perception and involves the potential willingness to act without having implemented ESS yet. Behavioral acceptance, however, has an active component and manifests itself in the reaction of the recipient being the actual use or lack of use of ESS. If the recipient shows a positive attitude towards ESS in the organization and has actually implemented ESS, one can call this an act of active acceptance [32].

\subsection{Research methodology}

The presented paper draws its results from a dataset composed of a survey amongst 101 manufacturing companies in Germany. As part of a two-stage research design, both qualitative and quantitative data was collected. The questionnaire for the quantitative study builds on the results of the qualitative analysis conducted in early 2016. The presented survey was conducted in late 2016 via an online survey tool. Potential participants were contacted personally before sending an email with the survey link. In total, the researchers contacted around 630 organizations that met the criteria and were located in the region in Germany of which 101 completed responses were received (16\% response rate). As stated before manufacturing companies show the tendency to a load profile characterized by peaks as well as a relatively high demand of energy, which is why the aim of this study is to gain insights regarding the attitude and behavior of manufacturing companies towards ESS. As shown in section 2.2 there are different modes of deployment of ESS. Based on the acceptance concept elaborated in section 3.1 the survey collected information from the respondents across six categories: awareness, interest, expectation/evaluation, energy consciousness, willingness to cooperate and demographics on energy consumption and size of the organizations. The questionnaire was compiled of 21 questions, which resulted in a total of 99 individual variables.

In this analysis, two different methodological approaches are used in order to gain further insights. Firstly, simple descriptive statistics are used to explore the demographics of the sample, the way energy is consumed in the organization and what level of energy conscious the organizations in question show. Secondly, bivariate analysis is deployed to identify the level of acceptance in the different organizations. After a factor analysis has been conducted, variables were grouped to form independent acceptance factors.

\section{Results}

\subsection{Sample and descriptive statistics}

Contact details of relevant organizations were obtained via different channels, such as affiliated industry association and partners as well as online research. Out of the 630 organizations that met the criteria, were located in the project region in Germany and whose data was accessible in some way, 101 organizations completed the questionnaire. Data obtained from such non-probability sampling process can, of course, not be statistically generalized as they do not necessarily depict a representative cross section of the population of interest. However, important characteristics were controlled in order to control the sampling process. Only companies labelled " $\mathrm{C}$ for manufacturing" following the Classification of Economic Activities of the Federal Statistic Office Germany (2008) were included in the sample as well as a relatively evenly distributed ratio of small, medium and large sized companies. In contrast to the qualitative analysis that only included energy intensive companies, the quantitative research includes both energy intensive and non-energy intensive companies. In cases where not much research has taken place a smaller and easily accessible sample can present a good starting point for further research [33].

Electric energy consumption ranges from 200 to $700.000 .000 \mathrm{kWh}$ with the average consumption 
being $17.488 .746 \mathrm{kWh}$. In order to gain a better understanding of the subsets included in the sample, different forms of clustering were used and statistically verified. One being the categorization by size following the definition of the EU Commission (2003) of small, medium- and large-sized enterprises. Considering aforementioned parameters, the organizations in the sample are with $46 \%$ (47) about half smaller sized companies, with $29 \%$ (29) about one third medium sized and $17 \%$ (17) large sized companies. ${ }^{\text {a }}$ Throughout the data analysis, the sample is divided in the subsets of small, medium and large sized companies where such clustering might be useful to understand certain motivations and perspectives. As one can see the sample is in a large proportion made up of smaller and medium sized companies and one could argue this may lead to a certain bias. However, from a structural point of view small and medium sized companies are relatively well represented in the considered region in Germany. Accompanying a sample that is relatively distributed among the classifications size-wise, there is also a relatively high standard deviation when looking at the electric energy consumption of the participants. The lowest consumption rate is $200 \mathrm{kWh}$ per year whereas the highest is $700,000,000 \mathrm{kWh}$ per year. With $61 \%$ the majority of the organizations do not produce electric energy in-house. The $39 \%$ that do produce in-house mainly produce electric energy via solar power $(61 \%)$ or Combined Heat and Power plants (27\%). Interesting to see is that most PV systems installed are relatively small and self-consumption rates are ranging around $20-30 \%$. This is most probably due to the fact that PV-systems built in Germany before 2012 are highly subsidized. In this case feeding in the generated electricity is more profitable than self-consumption.

The respondents show a tendency to relatively evenly distributed load profiles with $30 \%$ of the organizations in questions having an evenly distributed load profile with few to no peak loads. The numbers of peak loads the organizations were facing in one year ranges from 0 to 15,000 peaks per year. This number however is highly dependent on the product that is being produced and the way production takes place.

\subsection{Cooperation in a distributed energy system}

As shown before ESS can have a special role in a distributed energy system. In terms of industrial users, cooperation in order to share investments, resources needed and storage capacity seems to be a viable option. As the results show the majority of the organizations in question do not have any experience with cooperative ties with regard to their energy supply. However, they seem on an operative basis relatively open to exchange and publish their load profiles. Nevertheless, results indicate that with increasing depths of the cooperation, the organizations become more hesitant to follow a cooperative business model when supplying with energy. $70 \%$ of the sample generally agree that cooperative arrangements need to be made to maintain a high quality supply with electric energy in future.

When asked to state the main drivers to form cooperation in the field of energy supply, the researchers deliberately left out the profitability issue, being one of the main reasons for hindrance, in order to gain better insights on what cooperation could look like in the future. The majority of the respondents especially stress the fact of long-term planning security for their company as well as relatively low bureaucratic efforts. As seen in Figure 2, the response behavior of the organizations in the sample is relatively homogenous. The ranking in terms of relevance of the factors for organizations in order to implement ESS does not change dramatically with the size of the companies.

\footnotetext{
${ }^{\text {a }}$ Eight organizations did not specify their revenue and workforce and could not be allocated to a classification. Classification of size was drawn according to the classification of the European Commission.
} 


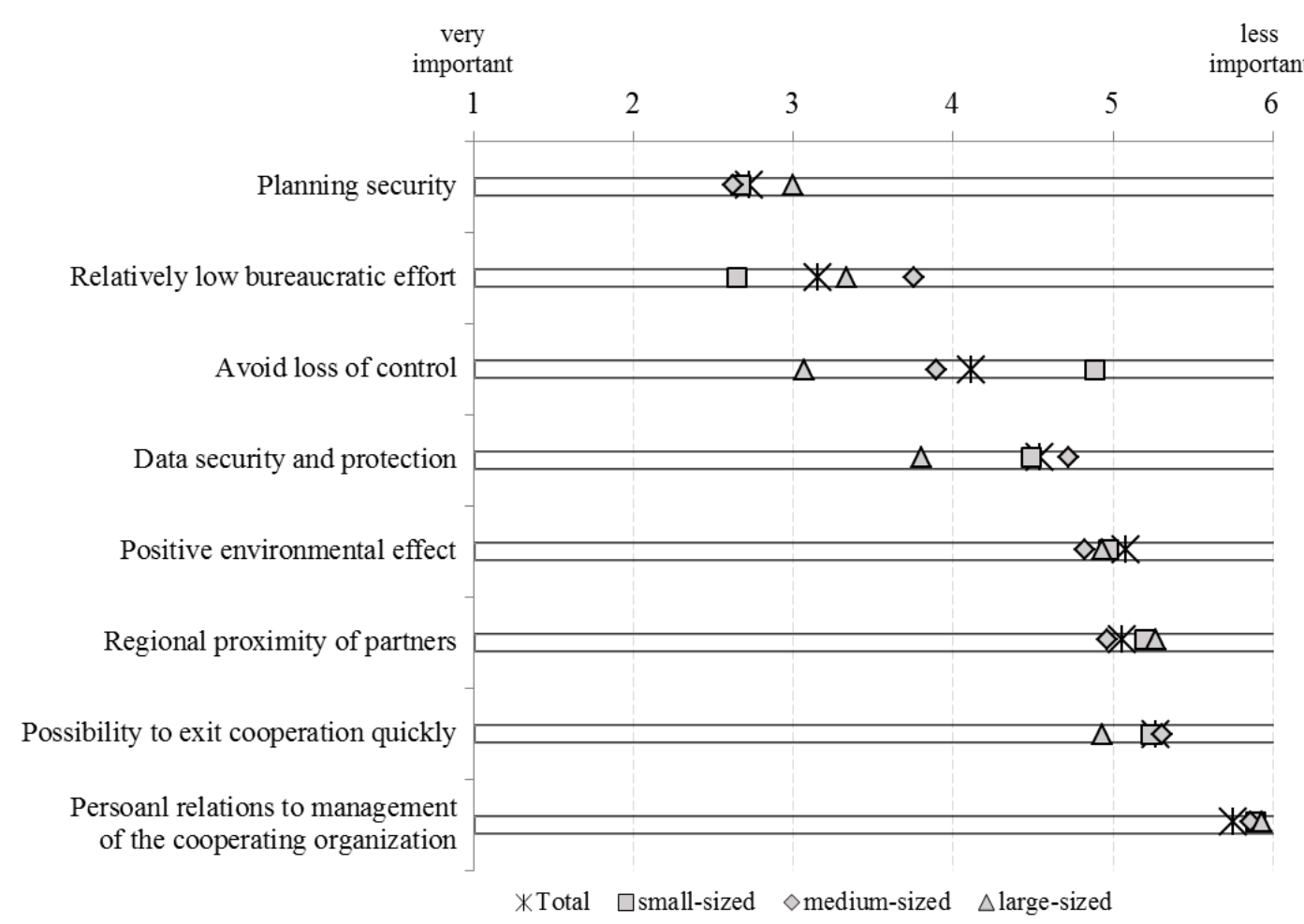

Fig. 2. Main drivers to form cooperation

However, it can be seen that smaller companies do favor less bureaucratic efforts in comparison to the other two subsets and in return do not mind the loss of control as much as the others do. Large- sized companies in contrast seem especially keen on the avoidance of control loss in comparison to the other subsets and would like to be able to exit the cooperation rather quickly.

Respondents were also asked to indicate their preference on a semantic differential with two opposing attributes for cooperation such as democratic or non-democratic decision making. The respondents favor with regard to cooperative arrangements for ESS fewer participants from private enterprises as well as a long-term cooperation and democratic decision making. Even though there is a general sense of willingness to cooperate, the majority of the sample seems to keep a certain distance to the topic of ESS in an industrial setting and lack in depths knowledge with regard to the topic. The ongoing transition of the German energy market suggests that organizations are well aware of the future changes. As seen in Table 1 the majority of the results range around the middle values of 3.0. In general it seems of interest that in comparison, the small-sized companies show higher values in the acceptance variables Awareness, Interest and Expectation/Evaluation.

The organizations in the sample are generally speaking relatively aware of ESS in an industrial setting. However, looking more closely respondents have heard of ESS from the media (Ø 3,84 on a 6-point scale) but do not show in depths knowledge about modes of deployment in their own organization ( point scale). No significant difference can be seen amongst the categories of small, medium and largesized organizations since they all show similar values. 
Table 1. Cumulative variables grouped by organization size

\begin{tabular}{l|l|l|l|l}
\hline Variable $^{\mathrm{b}}$ & $\begin{array}{l}\text { Mean small-sized } \\
(\mathrm{n}=47)\end{array}$ & $\begin{array}{l}\text { Mean medium-sized } \\
(\mathrm{n}=29)\end{array}$ & $\begin{array}{l}\text { Mean large-sized } \\
(\mathrm{n}=17)\end{array}$ & $\begin{array}{l}\text { Total } \\
(\mathrm{n}=101)\end{array}$ \\
\hline Awareness & 2,99 & 2,80 & 2,95 & 2,92 \\
\hline Interest & 2,98 & 2,46 & 2,41 & 2,74 \\
\hline Expectation/Evaluation & 3,98 & 3,62 & 3,32 & 3,74 \\
\hline Future profitability & 3,78 & 3,03 & 2,74 & 3,34 \\
\hline
\end{tabular}

With regard to the variable Interest a much more differentiated picture can be drawn. With decreasing size, the respondents show higher interest in the topic of ESS $(\varnothing 2,98$ on a 6-point scale for small organizations and $\varnothing 2,41$ on a 6-point scale for large organizations). Interesting to note is that smaller companies seem to be relatively better informed and share an idea of how to implement ESS in the future in comparison to the larger organizations. Whereas middle and large sized organizations show lower interest in ESS and are especially critical of ESS.

Accordingly the value with regard to Expectation/Evaluation is also higher amongst smaller-sized companies $(\varnothing 3,98$ on a 6-point scale) in comparison to larger-sized companies $(\varnothing 3,32$ on a 6-point scale). Again, the Expectation/Evaluation variable increases with decreasing size of the organization. When asked specifically whether ESS would be of interest to their organization in particular, $40 \%$ of the respondents stated that they do generally see a specific interest in ESS for their company whereas 60\% are not interested in ESS. Main focus of the interest in ESS is following the respondents the possibility of peak-shaving and to increase the consumption rate of self-generated energy. Organizations not interested mainly attribute their decision to the currently perceived unprofitability of ESS and the fact that ESS do not match their needs in terms of the amount of electric energy that is being consumed.

Even though a moderate awareness can be stated for the respondents in the sample, only 7 of the 101 organization have already implemented ESS in their organization. Looking at the state of implementation from the behavioral acceptance site shows that behavioral acceptance is low in the data drawn from the sample. However, the respondents evaluate a future profitability of ESS in industrial organizations rather positive and agree relatively strongly ( $\varnothing 4,80$ on a 6-point scale) on the fact that profitability is the main driver for future implementation of ESS in an industrial setting. These results also match the fact that the organizations in question show less interest in ESS due to the perceived unprofitability.

\section{Conclusion}

After having looked at the data of 101 manufacturing companies in Germany this paper examines the future role of ESS as well as current reasons for hindrance and perspectives for future growth of ESS in an industrial setting if desired for on a policy level.

Since small-sized companies seem to show higher interest rates than the other two subsets, it could be of interest to implement lighthouse projects with these organizations in order to draw attention to the different possible areas of deployment of ESS in an industrial setting. As the results of this survey show, even though possible ways of implementation exist for organization, they do not know the modes of deployment in detail. In their role as promoters regional policy makers could use such project in order to communicate and broaden perspective on ESS in an industrial setting. In this manner the interest that is currently generated by the media could be channeled and fuel a more substantial and individual discussion about ESS in an industrial setting.

As anticipated in the beginning, ESS are perceived as being unprofitable by the industry and the current market design in fact seems to lack adequate business models for ESS in organizations. However, as shown in section 2.2 the business cases do exist in theory but have not been recognized and

\footnotetext{
${ }^{b}$ Based on factor analysis relevant items were grouped and transformed into one variable. All scales are based on a 6-point scale ranging from "totally disagree" to "totally agree".
} 
implemented by the industry yet. As long as the perception of unprofitability hinders organizations to think possible solutions through and transfer those to their own organization, the adoption and diffusion of ESS seems very difficult. Organizations attribute their lack of interest mainly to the fact of unprofitability. If those unprofitability issues could be addressed and communicated accordingly, ESS could become a topic for many organizations in Germany and other parts of the world.

In stark contrast to the typical business model approach, cooperative business models in the field of ESS do not present a focus on the core competencies- for most organizations not lying in the field of energy generation or distribution- but rather a strategic approach to prevail in a competitive market and an opportunity to lower the overall energy costs in future [34]. However, cooperative models are quite suited in the field of RET and examples could possibly be drawn from the literature around Community Energy Projects and coopetition [35-37].

As the results show, the majority of respondents agree on the fact that cooperation will be part of the future energy system. As stated in the introduction, the question arises what business models can be developed in order to meet the necessity for cooperation? Cooperative business models in the field of industrial ESS offer the possibility to maximize- by combining different modes of deployment- profits and most importantly use the storage provided the best way possible. Since every ESS installed does have an effect on the environment, as especially rare resources such as Lithium are needed to build such storages, it is important to install as few ESS as possible and to use the ESS installed to its capacity where possible. But not only from an ecological point of view the interconnection of different consumers and renewable energy technologies makes sense as benefits can be enhanced when such technologies are interconnected and integrated into a smart grid [38]. Cooperation does meet some of the diverse needs in a distributed energy system. Especially organizations that run different load profiles and are able to manage their load accordingly could draw many advantages from the cooperative use of ESS. When looking at the current market design in Germany whether the RET-unit installed uses the grid or not plays an important role. With current law such micro-grids need to pay for using the grid. This can lead to unprofitability relatively quick and can impede the cooperative usage of ESS. Generally speaking, with current market design physical proximity is a must in order to install cooperative ESS due to the avoidance of using the grid. However, when individual ESS (from cooperations or households) need to be grouped in order to offer larger amounts of electricity and storage capacity, the grid connection issue needs to be addressed. It seems important to asses and evaluate certain problems stated by the industry and build up trust by promoting lighthouse projects and early adopters.

As the literature research suggests, the multiple roles of ESS in a distributed energy system are relatively clear from a technical point of view but lack decisive market implementation strategies. With the line between generation, transmission and distribution becoming more and more blurry with new RET, such as ESS entering the market and organizations need to find their place within this process. The results of this paper strongly suggest that further research is undertaken in order to develop and design cooperative business models in the field of industrial ESS-usage in order to support the diffusion of ESS and the decentralized character of the German Energy Transition. With these first insight on what cooperative arrangements could look like and the empirical starting point of the status-quo from Germany regarding ESS in the industry, researchers can develop more in-depths research designs that instead of addressing broader aspect of acceptance of ESS in the industry, focus on the acceptance of future cooperative business models in the field of industrial ESS.

\section{Acknowledgements}

The authors are grateful to the Volkswagen Foundation and the University of Applied Sciences Osnabrueck for the funding and support of this research under the interdisciplinary project "EOS- Energy Storage Solutions for the region Osnabrueck-Steinfurt". 


\section{References}

[1] Divya KC, Ostergaard J. Battery energy storage technology for power systems-An overview. Electr. Power Syst. Res. 79 (2009): 511-520.

[2] Buttler Alexander SH, Kampf der Studien. Eine Metaanalyse aktueller Energiesystemstudien zum Bedarf an Speichern und konventionellen Kraftwerken im Kontext der Annahmen und der historischen Entwicklung., n.d. [Online]. Available: https://www.klimaschutz-

niedersachsen.de/_Resources/Persistent/9b41ee59137f5a5497a610c876099825ac114842/TUM_201601_Kampf-derStudien_Metaanalyse.pdf (accessed June 8, 2017).

[3] Sterner M, Stadler I., Energiespeicher - Bedarf, Technologien, Integration, Springer Berlin Heidelberg, Berlin, Heidelberg, 2014.

[4] BDEW, Stromverbräuche nach Sektoren. Idustrie., (2015). [Online]. Available: https://www.bdew.de/internet.nsf/id/DE_Energiedaten\#cat/Daten\%2FGrafiken\%5CEnergie allgemein\%5CEnergiedaten\%5C3. Stromversorgung/3-2-endenergieverbrauch-strom-nach-industriezweigen-de (accessed June 8, 2017).

[5] Del R P. Analysing future trends of renewable electricity in the EU in a low-carbon context. Renew. Sustain. Energy Rev. 15 (2011): 2520-2533.

[6] Mohd A, Ortjohann E, Schmelter A, Hamsic N, Morton D. Challenges in integrating distributed Energy storage systems into future smart grid. 2008 IEEE Int. Symp. Ind. Electron. (2008) 1627-1632.

[7] Luo X, Wang J, Dooner M, Clarke J. Overview of current development in electrical energy storage technologies and the application potential in power system operation. Appl. Energy. 137 (2015): 511-536.

[8] Lund PD, Lindgren J, Mikkola J, Salpakari J. Review of energy system flexibility measures to enable high levels of variable renewable electricity, Renew. Sustain. Energy Rev. 45 (2015): 785-807.

[9] Castillo A, Gayme DF. Grid-scale energy storage applications in renewable energy integration: A survey. Energy Convers. Manag. 87 (2014): 885-894.

[10] Rahbar K, Moghadam MRV, Panda SK, Reindl T. Shared energy storage management for renewable energy integration in smart grid. 2016 IEEE Power Energy Soc. Innov. Smart Grid Technol. Conf. (2016) 1-5.

[11] BVES, Faktenpapier Energiespeicher. Rechtsrahmen. Geschäftsmodelle. Forderungen., n.d. [Online]. Available: https://www.magdeburg.ihk.de/blob/mdihk24/innovation/downloads/3351856/e984f6907e62e66e9e9a550888b1ba70/Faktenp apier-Energiespeicher-data.pdf (accessed June 8, 2017).

[12] Kondziella H, Brod K, Bruckner T, Olbert S, Mes F. Stromspeicher für die „Energiewende“ - eine akteursbasierte Analyse der zusätzlichen Speicherkosten. Zeitschrift Für Energiewirtschaft. 37 (2013): 249-260.

[13] E. Fahlbusch, Batterien als Energiespeicher : Beispiele, Strategien, Lösungen, Beuth, 2015.

[14] BDEW, Realistische Schritte zur Umsetzung von Smart Grids in Deutschland, (2013). ttps://www.bdew.de/internet.nsf/id/EBA1B69FB989A44FC1257B09003BD1A3/\$file/130204_BDEW-

Roadmap_Summery_neu.pdf.

[15] Simon R, Nachfrageseitige Flexibilitätsoptionen: Demand-Side-Management, Energiespeicher und Regelenergie, in: Ind. Energiestrategie, Springer Fachmedien Wiesbaden, Wiesbaden, 2017: 255-273.

[16] Matzen FJ, Wertschöpfungsorientiertes Energiecontrolling, in: Ind. Energiestrategie, Springer Fachmedien Wiesbaden, Wiesbaden, 2017: 429-458.

[17] Zafirakis D, Elmasides C., Sauer DU, Leuthold M, Merei, Kaldellis JK, Vokas G, Chalvatzis KJ. The multiple role of energy storage in the industrial sector: Evidence from a Greek industrial facility, Energy Procedia. 46 (2014)" 178-185.

[18] Atabay D, Dornmair R, Hamacher T, Keller F, Reinhart G. Flexibilisierung des Stromverbrauchs in Fabriken, 13. Symp. $\begin{array}{llll}\text { Energieinnovation,. } & \text { (2014) } & \text { [Online]. } & \text { Available: }\end{array}$ http://portal.tugraz.at/portal/page/portal/Files/i4340/eninnov2014/files/lf/LF_Keller.pdf.

[19] Vogt T, Kempen S, Böcker J. Die Rolle von Batteriespeichern in KMU-Microgrids, Bwk. 66 (2014): $52-57$.

[20] Wüstenhagen R., Wolsink M.,. Bürer M.J, Social acceptance of renewable energy innovation: An introduction to the concept, Energy Policy. 35 (2007) 2683-2691.

[21] Menges R., Beyer G., Energiewende und Übertragungsnetzausbau: Sind Erdkabel ein Instrument zur Steigerung der gesellschaftlichen Akzeptanz des Leitungsbaus? Eine empirische Untersuchung auf Basis der Kontingenten Bewertungsmethode, Z Energiewirtsch. 37 (2013): 277-295.

[22] Sütterlin B., Siegrist M, Public acceptance of renewable energy technologies from an abstract versus concrete perspective and the positive imagery of solar power, (2017).

[23] Bertsch V., Hall M., Weinhardt C., Fichtner W. Public acceptance and preferences related to renewable energy and grid expansion policy: Empirical insights for Germany, Energy. 114 (2016) 465-477.

[24] Sardianou E., Genoudi P., Which factors affect the willingness of consumers to adopt renewable energies?, Renew. Energy. 57 (2013) 1 
[25] Zaunbrecher BS, Ziefle M. Social Acceptance and Its Role for Planning Technology Infrastructure - A Position Paper, Taking Wind Power Plants as an Example, in: Proc. 4th Int. Conf. Smart Cities Green ICT Syst., 2015: 60-65.

[26] Fischer D. Wolfgang; Schumann, Große Stromspeicher aus Sicht der Bevölkerung, Energiewirtschaftliche Tagesfragen. 66 (2016) $\quad 81-85 . \quad$ http://et-energieonline.de/AktuellesHeft/WeitereThemen/tabid/71/Year/2016/Month/9/NewsModule/425/NewsId/1872/Groe-Stromspeicheraus-Sicht-der-Bevolkerung.aspx (accessed June 8, 2017).

[27] Griese KM., Wawer T., Böcher R., Suffizienzorientierte Geschäftsmodelle am Beispiel von Stromspeichern Zukunftsfähige Ansätze in der Energiewirtschaft Sufficiency of electricity storage business models, Zeitschrift Für Energiewirtschaft. 40 (2016) 57-71.

[28] Müller-Böling D., Müller M. Akzeptanzfaktoren der Büro- kommunikation, 1986. https://www.mueller-boeling.de/wpcontent/uploads/2016/05/Pub-1986-Akzeptanzfaktoren-der-Buerokommunikation.pdf (accessed June 8, 2017).

[29] Schweizer-Ries P., Energy sustainable communities: Environmental psychological investigations, Energy Policy. 36 (2008) :4126-4135.

[30] Kollmann T., Akzeptanz innovativer Nutzungsgüter und -systeme: Konsequenzen für die Einführung von Telekommunikations- und Multimediasystemen, Gabler, 1998.

[31] Gribel L., Regier S. Erfolgsfaktoren der Akzeptanz nachhaltiger Energietechnologien, Eul, J, 2014. https://www.eulverlag.de/shop/eul/apply/viewdetail/id/2406/ (accessed June 8, 2017).

[32] Dethloff C., Akzeptanz und Nicht-Akzeptanz von technischen Produktinnovationen, Pabst Science Publ, 2004.

[33] Henry G.T., Practical sampling, n.d. https://uk.sagepub.com/en-gb/eur/practical-sampling/book3152 (accessed June 8, 2017).

[34] Morris , M. Schindehutte M.H., Richardson J., Allen J., Is the business model a useful strategic concept? Conceptual, theoretical, and empirical insights, J. Small Bus. Strateg. $17 \quad(2006)$ 27-50. http://scholar.google.at/scholar?q=MORRIS+business+model\&btnG=\&hl=de\&as_sdt=0\&sciodt=0\&as_ylo=2006\&as_yhi=20 06\&cites $=14064565542954624250 \&$ scipsc $=\# 1$.

[35] Huybrechts B., Mertens S., THE RELEVANCE OF THE COOPERATIVE MODEL IN THE FIELD OF RENEWABLE ENERGY, (2014) 193-212.

[36] Yildiz Ö., Rommel J, Debor S., Holstenkamp L., Mey F., M J.R.ller, J. Radtke, J. Rognli, Renewable energy cooperatives as gatekeepers or facilitators? Recent developments in Germany and a multidisciplinary research agenda, Energy Res. Soc. Sci. 6 (2015) 59-73.

[37] Ritala P., Sainio L.M., Coopetition for radical innovation: technology, market and business-model perspectives Coopetition for radical innovation: technology, market and business-model perspectives, Technol. Anal. Strateg. Manag. 26 (2014) $155-169$.

[38] Ellabban O., Abu-Rub H., Blaabjerg F., Renewable energy resources: Current status, future prospects and their enabling technology, Renew. Sustain. Energy Rev. 39 (2014) 748-764. 